\title{
Flowering Induction in Camellia chrysantha, a Golden Camellia Species, with Paclobutrazol and Urea
}

\author{
Xiao-Juan Wei ${ }^{1}$, Jinlin Ma, Kai-Xiang Li, and Xiao-Jing Liang \\ Guangxi Key Laboratory of Characteristic Non-wood Forest Cultivation and \\ Utilization, Guangxi Forestry Research Institute, Nanning, Guangxi 530002, \\ People's Republic of China

Haiying Liang ${ }^{1}$
Department of Genetics and Biochemistry, Clemson University, Clemson,
SC 2934

Additional index words. early flowering, exogenous phytohormone, golden camellia flower, reproduction

\begin{abstract}
The flowers of Camellia chrysantha, commonly named as golden camellia, are treasured for their unique yellow color and are popularly used for tea. Compared with common camellia flowers that are either red, purple, pink, or white, golden camellia flowers are rare and are in high market demand. Our study was aimed to induce flowering in juvenile $C$. chrysantha grafted plants with urea and paclobutrazol (PBZ), a growth retardant. Generally, it takes 6-8 years for $C$. chrysantha seedlings and 5-6 years for grafted plants to set flower buds. With a $4 \times 4$ factorial design, four dosages of urea $(1,3,5$, or $8 \mathrm{~g} /$ plant $)$ and four concentrations of $\mathrm{PBZ}(50,150,350$, and $750 \mathrm{ppm})$ were tested on 4-year-old $C$. chrysantha grafted plants. Significant interaction between urea and $P B Z$ was observed, and nine of the 16 combinations produced significantly more flower buds than the control, although not all flower buds could open because of abscission. High concentrations of PBZ and high dosages of urea were generally associated with severe defoliation and slow growth of basal stem diameter. When taking bud abscission into account, combinations of $150 \mathrm{ppm} P B Z$ with $1 \mathrm{~g}$ urea and $350 \mathrm{ppm}$ PBZ with $3 \mathrm{~g}$ urea resulted in significant flowering in juvenile $C$. chrysantha grafted plants without negative effects on vegetative growth and flower bud size and severe defoliation. This is the first report on flowering induction in a golden camellia species using juvenile plants. Our results suggest that application of optimized PBZ and urea doses can be a potential means for manipulation of early flowering in golden camellia species.
\end{abstract}

Commonly referred to as cha-hua in Chinese, camellia flowers have been cultivated and treasured in the Orient for thousands of years and now are grown throughout the world in botanical gardens and home greenhouses (Ming, 2000; Zhu et al., 2007). Their flowers bloom from winter to spring, in a range of colors, forms, fragrances, and sizes. Until fairly recently, camellia flower coloration was restricted to red, purple, pink, and white. Yellow is a long-sought-after color. Traditional breeding approaches were tried for nearly half a century, yet were unsuccessful in producing a yellow flower

Received for publication 25 May 2017. Accepted for publication 19 Sept. 2017.

This research was jointly supported by a State Bureau of Forestry 948 project (\#2014-4-14), Guangxi Key Laboratory of Characteristic Non-wood Forest Cultivation and Utilization (\#15-A-04-01), Distinguished Expert Special Fund for the award, Physiology of Flowering of Major Cash Non-wood Crop Species in Guangxi, a basic research project of Guangxi Forestry Research Institute (\#201603), and Clemson University.

${ }^{1}$ Corresponding authors. E-mail: 13978899665@126. com or hliang@clemson.edu.
(Park, 2000; Shinichi et al., 2004). Therefore, when a camellia with deeply golden-yellow petals was first discovered in Guangxi, China, by $\mathrm{Hu}$ (1965), it generated great excitement in the horticultural sector of the world. $\mathrm{Hu}$ (1965) first named the species as Theopsis chrysantha. This taxon was subsequently transferred to the genus Camellia by Tuyama (1975) as Camellia chrysantha (Hu) Tuyama. Later taxonomic studies proved that $C$. chrysantha was the same as Camellia nitidissima Chi, which was introduced much earlier in the 1930s, yet received no attention from the public or horticulturists (Deng et al., 2000). Since then, both names have been used in publications.

Camellia chrysantha, along with other similar yellow-flowering camellia species that were discovered later, are grouped into section Chrysantha Chang (Theaceae), which comprises more than 24 species and five variants and are commonly known as golden or yellow camellias (Zhuang, 2008). Because of their large unique golden flowers $(5-10 \mathrm{~cm}$ in width) and high ornamental value, these yellow camellias are honored as "the Queen of Camellia" (Liang, 1993). Unlike other camellia species that are globally cultivated, this subgroup occurs in a narrow region of southwest China and North Vietnam, ranging between $20^{\circ} 32^{\prime}-23^{\circ} 53^{\prime} \mathrm{N}$ and $104^{\circ}-108^{\circ} 56^{\prime} \mathrm{E}$ and at altitudes of 50 $650 \mathrm{~m}$ (Gao, 2005; Zhang and Ren, 1998). In recent years, there has been a dramatic decline in natural population size for these species because of a combination of factors such as increasing anthropogenic pressure, deforestation, and destructive collection of seedlings (Xing, 2005). As a result, yellow camellias have also unfortunately earned the nickname "the Giant Panda of the Plant Kingdom" because they have been listed as a first-grade endangered species in China (Xu, 1995). In addition to its importance in floriculture, golden camellias are priced for their beneficial components in leaves and flowers. According to Song et al. (2011), golden camellias contain more diverse phenolic compounds compared with commonly consumed tea leaves (Camellia sinensis). Ellagitannins, proanthocyanidins, taxifolin deoxyhexose, apigenin derivatives, kaempferol derivative, quercetin derivatives, glucosylisorhamnetin, (epi)catechin-(epi) afezelechinpolymerisations, and platphylloside were found in golden camellias, whereas negligible in common tea leaves. Many of these compounds have been shown to possess antioxidant and anti-inflammatory activities that may be beneficial to health (Lin et al., 2013; Wang et al., 2015). Unlike common tea leaves, no caffeine was detected in the six species of golden camellias included in the study of Song et al. (2011). Currently, golden camellias have been introduced to Japan, Australia, and North America as a genetic resource for commercial cultivation (Lü et al., 2013; Nybom and Bartish, 2000; Zhuang, 2008). Because flowers are usually harvested before seeds are set, golden camellia seeds are not readily available. As a result, grafting and cutting are two main propagation methods for golden camellia.

Golden camellia flower, bud, leaf, and seed cake are popularly used as tea in China. However, the price is high, particularly for flower tea. According to Su (2010) and a report in China Daily published in Sept. 2014 (http://guangxi.chinadaily.com. $\mathrm{cn} /$ hechi/2014-09/05/content 18551816.htm), the price of golden camellia flower tea is about 30,000 Yuan $(\approx \$ 4600)$ per kilogram, whereas bud tea is about 20,000 Yuan $(\approx \$ 3050)$, seed cake tea 1050 Yuan (\$165), and leaf tea about $300(\approx \$ 460)$ Yuan. Hence, there is a large market for golden camellia flowers. Whereas mature golden camellias can produce as many as 300 flowers per tree, it generally takes $6-8$ years for seedlings and 5-6 years for grafted plants to start setting flower buds (Chai et al., 2009; Jiang and Zhao, 1997). This long juvenile phase not only hinders conventional breeding, but also has an adverse impact on economic incomes for breeders. Our study was aimed to induce flowering in juvenile C. chrysantha. We assessed the effects of different combinations of nitrogen fertilizer, urea $\left[\mathrm{CO}\left(\mathrm{NH}_{2}\right)_{2}\right]$, and growth regulator, $\mathrm{PBZ}$ [(2RS,3RS)-1(4-chlorophenyl)-4,4-dimethyl2-(1H-1,2,4-triazol-1-yl)pentan-3-ol, PBZ], 
on flowering induction. The objective was to identify optimal combinations that could promote flowering in young $C$. chrysantha plants while minimizing the undesirable effects.

Paclobutrazol is a triazole-type cytochrome $\mathrm{P}_{450}$ inhibitor used extensively in horticulture as a plant growth retardant and fungicide. Its dual biological functions are because of the facts that PBZ possesses several isomers and formulations of PBZ consist of a mixture of two stereoisomers, each with its own unique biological activity (Lurssen, 1988). One isoform targets the ecdysis of insects and fungal sterols, whereas the other inhibits gibberellin (GA) biosynthesis by blocking the oxidative conversion of ent-kaurene to kaurenoic acid in plants, leading to decrease in endogenous GA levels and abscisic acid catabolism (Fletcher and Hofstra, 1988; Rademacher, 2000). PBZ has been found to be predominantly effective in inducing and manipulating flowering or fruiting in plants such as mango (Blaikie et al., 2004; Kulkarni, 1988; Yadav et al., 2005), Eucalyptus (Griffin et al., 1993), Consolida orientalis (oriental knight's-spur) (Mansuroglu et al., 2009), plum (Oliveira and Browning, 1993), red camellia hybrids (Camellia $\times$ Williamsii) (Wilkinson and Richards, 1988), and grapes (Christov et al., 1995). However, as an antagonist of GA, which promotes cell division and/or cell elongation in plants and is relatively abundant in juvenile plant tissues, PBZ reduces stem length (e.g., Mabvongwe et al., 2016; Pal et al., 2016). Adverse effects on fruit shape, leaf size and color, and timing of anthesis have also been reported (Stinchcombe et al., 1984; Williams, 1984; Zheng et al., 2012).

Nitrogen $(\mathrm{N})$ is an essential nutrient for healthy plant growth and development, and urea is the predominant form of $\mathrm{N}$ fertilizer used worldwide. In addition to promoting vegetative growth and green coloration of foliage, nitrogen fertilizers can improve crop yield and quality. Elimination of $\mathrm{N}$ in cotton production could lead to an estimated yield reduction of $37 \%$ (Stewart, 2002). According to George and Nissen (1992), nitrogen alone increased the peach fruit set by $48 \%$ and tree fruit yields by about $40 \%$, and when nitrogen and PBZ were applied together, the yield efficiency was estimated to increase by about $60 \%$. Application of both nitrogen fertilizer and PBZ also substantially increased the occurrence of precociously flowering Eucalyptus trees over that of either treatment applied alone (Williams et al., 2003). Here, we report for the first time that application of optimized PBZ and urea doses can be a potential strategy to achieve early flowering in golden camellia species.

\section{Materials and Methods}

Plant materials and study site. Partially lignified $C$. chrysantha branches (0.5- to 1year-old) were grafted in Aug. 2012 on 1.5year-old Camellia osmantha rootstocks. As a fast-growing oil camellia species, $C$. osmantha can tolerate drought, flooding, and high temperatures (Wang et al., 2014). Grafting compatibility of $C$. chrysantha on $C$. osmantha is high, with a survival rate of at least 90\% (Ma et al., 2013). The grafted plants were grown in nonwoven fabric garden bags (30 $\mathrm{cm}$ in height, $25 \mathrm{~cm}$ in diameter) containing $85 \%$ yellow podzolic soil, $10 \%$ coconut husk, and 5\% fertilizer (v:v:v). Major components of the fertilizer included $\mathrm{Ca}_{3}\left(\mathrm{PO}_{4}\right)_{2}, \mathrm{CaSiO}_{3}$, and $\mathrm{MgSiO}_{3}$. Initially the plants were covered with plastic to ensure high humidity ( $80 \%$ to $90 \%)$ until new shoots sprouted. Fungicide carbendazim (CAS No. $10605-21-7)$ or zineb (CAS No. ý12122$67-7)(0.3 \%$ to $0.5 \%)$ were sprayed on the plants every $10-15 \mathrm{~d}$ for disease control. The study site was the Camellia Nursery of Guangxi Forestry Research Institute (latitude $22^{\circ} 56^{\prime} \mathrm{N}$, longitude $108^{\circ} 21^{\prime} \mathrm{E}, 95 \mathrm{~m}$ above sea level), China. With a subtropical monsoon climate, the area has distinct dry and wet seasons. The average annual temperature is $21.8^{\circ} \mathrm{C}$, while the average in January is $11.8{ }^{\circ} \mathrm{C}$ and $27.6{ }^{\circ} \mathrm{C}$ in July. The record low and high temperatures are $-1.5{ }^{\circ} \mathrm{C}$ and $39.4{ }^{\circ} \mathrm{C}$, respectively. Annual accumulated temperature of at least $10^{\circ} \mathrm{C}$ is $7200^{\circ} \mathrm{C}$. The rainy season is during May to September, with an annual precipitation of over $1300 \mathrm{~mm}$. All plants were maintained under a shade canopy that was $\approx 2.25 \mathrm{~m}$ in height and blocked $70 \%$ to $80 \%$ sunlight.

Experimental design. A $4 \times 4$ factorial design was used to test the effects of urea and PBZ on flower induction (Table 1). Urea was applied to root area at a level of 1, 3, 5, or $8 \mathrm{~g} /$ tree on $16 \mathrm{Apr}$. 2016. Four different concentrations of PBZ $(50,150,350$, and 750 ppm) were prepared in $1 \mathrm{~L}$ solution and then applied onto roots on Apr. 26, May 29, and June 24, 2016, respectively. Urea was purchased from Jimei Hengsheng Chemical Engineering Co. Ltd. and contained at least 46.4\% nitrogen (Chinese Executive standard code GB2440-2001). PBZ (CAS No. 7673862-0) was purchased from Anyang Quanfeng Biological Technology Co. Ltd. (He Nan Province, China) and contained $95 \%$ effective components. The control plants (CK) were managed in the same way as the treated group except with no urea and PBZ applied in garden bags. There were three plants per treatment type and control. All plants included in the study were similar in height and basal stem diameter before the treatments were applied, and were sprayed to runoff with $800 \mathrm{ppm}$ PBZ on 10 May 2016. None of these plants ever flowered before 2016.

Sample and data collection. Flower buds were first counted on 19 Sept. 2016 when they became distinguishable from vegetative buds (Fig. 1A-C) and were counted again on 17 Jan. 2017 when blooming started (Fig. 1D-F). Flower buds are round and big, while vegetative buds are thin and long. Defoliation occurred after treatments. In January 2017, defoliation percentage was estimated and categorized into three groups: light $(<30 \%)$, medium $(30 \%$ to $50 \%)$, and severe $(>50 \%)$. Two or three leaves were collected on 1 Apr. 2016 (before treatment), 27 Sept. 2016 (rapid flower bud development), and 18 Jan. 2017 (budbreak) from each plant and pooled based on the treatment type before being sent to the core facility at Guangxi Forestry Research Institute for measurement of $\mathrm{C}$ and $\mathrm{N}$ contents by standard $\mathrm{K}_{2} \mathrm{Cr}_{2} \mathrm{O}_{7} / \mathrm{H}_{2}$ $\mathrm{SO}_{4}$ oxidation and Kjeldahl procedures, respectively. Plant height, stem diameter at ground level, and flower bud size (length and width, at least six buds if available) were measured on 17 Jan. 2017. On the same date, relative chlorophyll levels of leaves with leaf plastochron index of 4-7 were measured using a Konica Minolta SPAD-50 chlorophyll meter (Konica Minolta, Japan). One measurement was recorded for each leaf.

Data analysis. The Shapiro-Wilk test was first performed to determine if the flower bud count data were normally distributed, and Levene's test was used to assess the equality of variances. Generalized linear models are then used to evaluate effects of treatments on flower counts when data were independent and the standard linear model assumptions were violated (Littell et al., 2006). The Tukey-Kramer test was used for multiple comparisons. All statistical analyses were performed using Statistical Analysis System (SAS) (SAS Institute, Inc., 2009), and significance level cutoff was set at $P<0.05$.

\section{Results}

Effects of urea and PBZ on flower bud induction. All plants used in our study produced flower buds for the first time in 2017 except for two plants in the T1 treatment $(1 \mathrm{~g}$ urea $+50 \mathrm{ppm}$ PBZ), two plants in T5 (3 g urea $+50 \mathrm{ppm}$ PBZ), and one plant in T12 ( $5 \mathrm{~g}$ urea +750 ppm PBZ). The three control plants produced a total of eight flower buds in Sept. 2016. Statistical analysis showed that

Table 1. A $4 \times 4$ factorial design for evaluating the effects of urea and paclobutrazol (PBZ) combinations on flower induction in Camellia chrysantha.

\begin{tabular}{|c|c|c|c|c|}
\hline \multirow[b]{2}{*}{ Urea treatment per plant (date: 16 Apr. 2016) (g) } & \multicolumn{4}{|c|}{ PBZ treatment (date: 26 Apr. 2016, 29 May 2016, 24 June 2016) } \\
\hline & $50 \mathrm{ppm}$ & $150 \mathrm{ppm}$ & $350 \mathrm{ppm}$ & $750 \mathrm{ppm}$ \\
\hline 1 & T1 & $\mathrm{T} 2$ & T3 & T4 \\
\hline 3 & T5 & T6 & $\mathrm{T} 7$ & $\mathrm{~T} 8$ \\
\hline 5 & T9 & $\mathrm{T} 10$ & $\mathrm{~T} 11$ & $\mathrm{~T} 12$ \\
\hline 8 & $\mathrm{~T} 13$ & $\mathrm{~T} 14$ & $\mathrm{~T} 15$ & T16 \\
\hline
\end{tabular}


seven of the 16 treatment types, T1, T5, T6 (3 g urea +150 ppm PBZ), T12, T13 (8 g urea + $50 \mathrm{ppm}$ PBZ), T14 (8 g urea $+150 \mathrm{ppm}$ PBZ), and T16 (8 g urea +750 ppm PBZ), resulted in a similar flower bud number to the control. In contrast, treatment types of T2 (1 g urea + 150 ppm PBZ), T3 (1 g urea + 350 ppm PBZ), T4 (1 g urea + 750 ppm PBZ), T7 (3 g urea +350 ppm PBZ), T8 (3 g urea + 750 ppm PBZ), T9 (5 g urea + 50 ppm PBZ), T10 (5 g urea + 150 ppm PBZ), T11 (5 g urea $+350 \mathrm{ppm}$ PBZ), and T15 (8 g urea + $350 \mathrm{ppm}$ PBZ) significantly increased the flower bud number. Thus, these treatment types were effective in flower induction (Fig. 2, dark color bars).

Likely because of the competition for nutrition, an average of $40.6 \%$ of the flower buds observed in Sept. 2016, were lost by mid-January when flower buds started to break. There was a moderate positive correlation between initial flower bud number and dropping rate, with a Pearson $R$ value of 0.54 and a $P$ value of 0.03 . However, after this abscission, plants receiving the $\mathrm{T} 2, \mathrm{~T} 3, \mathrm{~T} 7$, and T11 treatments still had significantly more flowers and flower buds than the control group $(11,11,16$, and 14 , respectively, vs. two per tree) (Fig. 2, light color bars). There was no significant difference among these four treatment groups, and their average number of combined flowers and flower buds was 13 per plant. In comparison, the control group had only two flowers per plant. Whereas T3, T7, and T11 differed in urea amount, 1, 3, or $5 \mathrm{~g} /$ tree, respectively, they all included three times' application of $350 \mathrm{ppm}$ PBZ. This indicates that in combination with $350 \mathrm{ppm}$ PBZ, applying more than $1 \mathrm{~g}$ of urea per tree is not necessary because it did not result in extra flowers. In fact, when the applied urea reached $8 \mathrm{~g} /$ tree
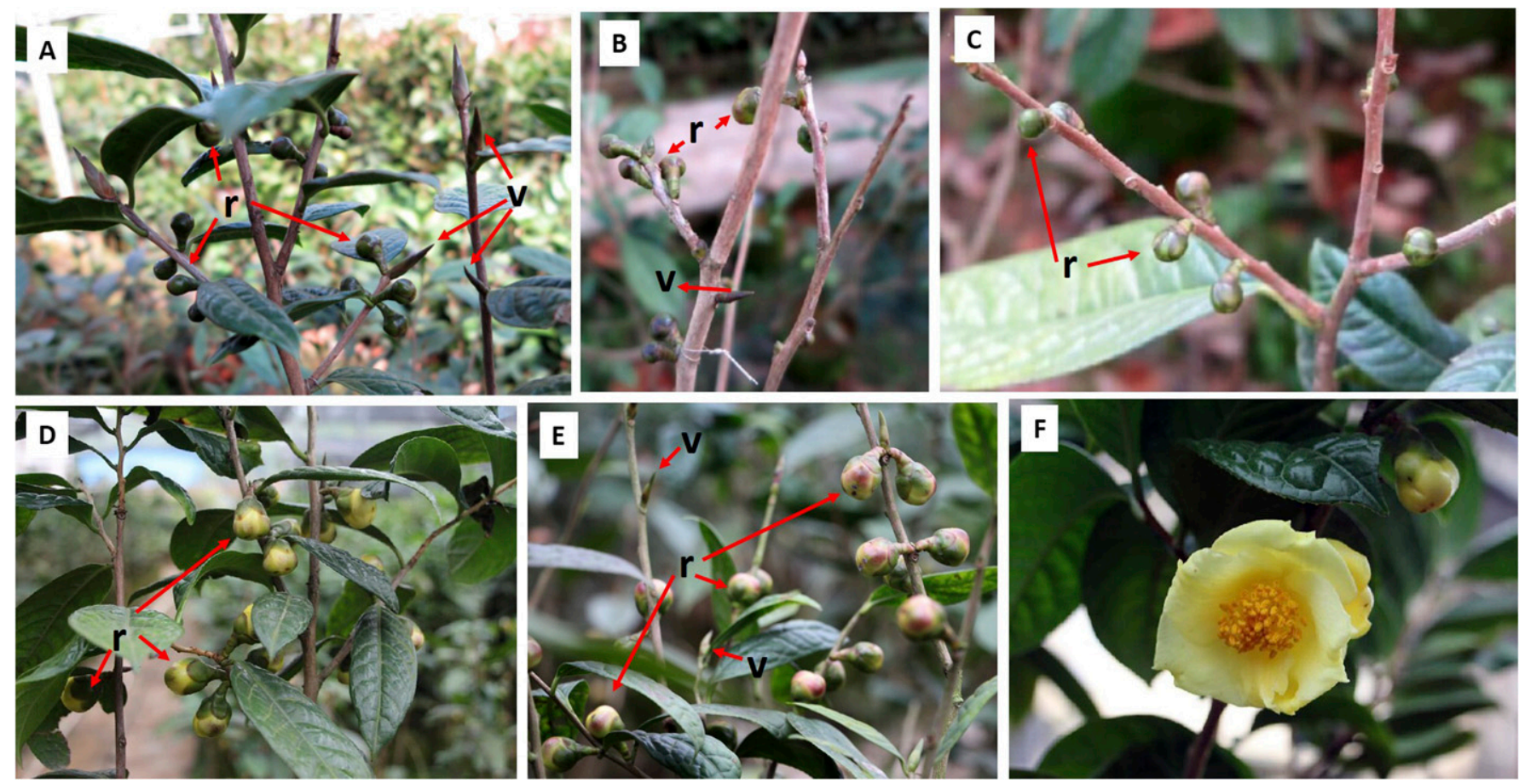

Fig. 1. Vegetative and reproductive buds and flower of golden camellia. (A) Buds in late Sept. 2016 without abnormal defoliation. (B, C) Buds in late Sept. 2016 with severe abnormal defoliation. (D, E) Buds in mid-Jan. 2017. (F) Flower in late Jan. 2017. $r=$ flower buds; $v=$ vegetative bud.

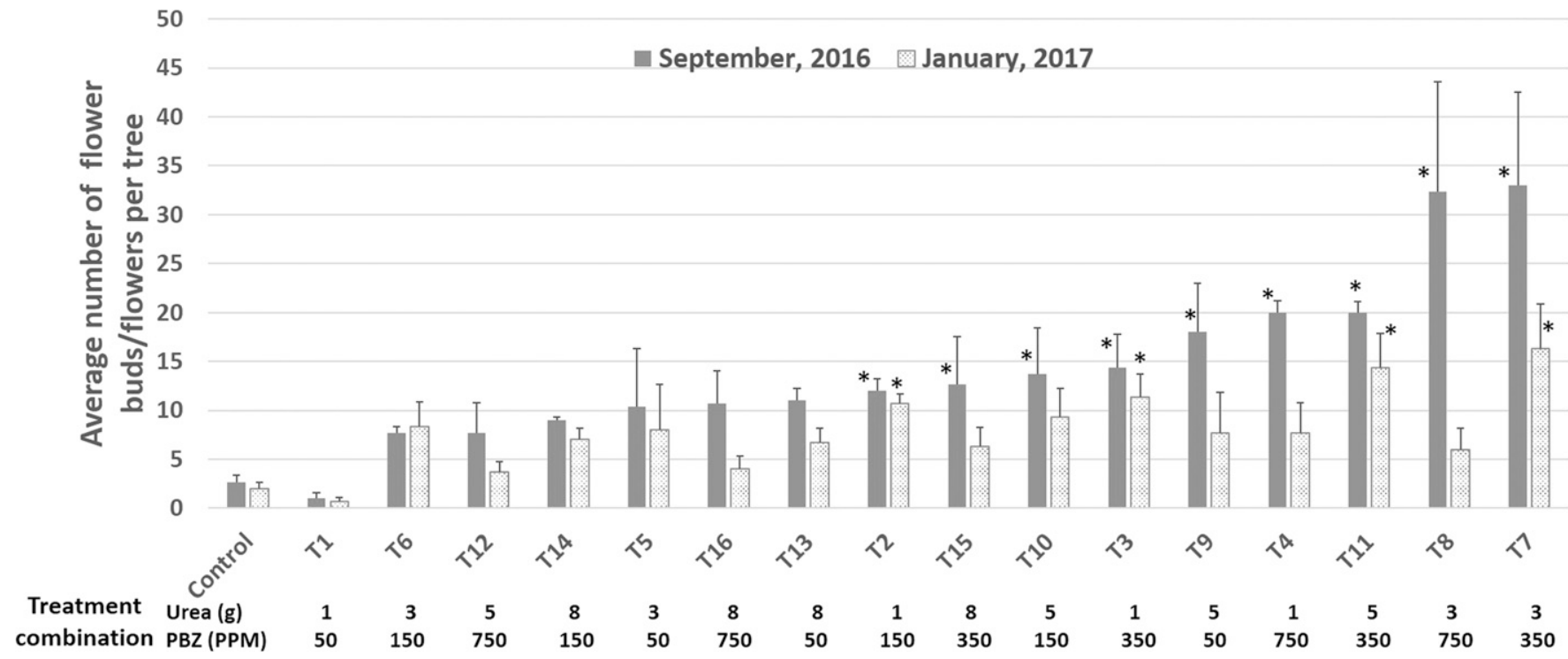

Fig. 2. Average number of flower and flower bud per Camellia chrysantha tree in Sept. 2016 and Jan. 2017. T1-T16: treatments with different combinations of paclobutrazol and urea. * indicates significant difference from control at $P<0.05$. 
(T15, in combination with 350 ppm PBZ), $50 \%$ of flower buds were lost by January, and the number of remaining flower buds was not statistically different from the that of the control group, although more flower buds were produced when compared with the control in September.

Flower buds on plants receiving treatments of T4, T7, T8, T11, T12, T15, or T16 had a smaller diameter than the control (Fig. 3, dark color bars). The T7-, T8-, and T12-treated plants also had a smaller bud length than the control (Fig. 3, light color bars). Whereas a weak negative correlation was found between the flower bud number and size, the result was not significant at $P<$ 0.05 . Overall, flower buds obtained in our study averaged $14.6 \pm 2.7 \mathrm{~mm}$ in diameter and $16.2 \pm 2.5 \mathrm{~mm}$ in length in mid-January when they started to break, with a range of 10.9-17.7 $\mathrm{mm}$ and $12.5-18.5 \mathrm{~mm}$, respectively (Fig. 1F). There was a strong correlation between flower bud diameter and length $(R=0.85, P<0.00001)$.

Effects of urea and PBZ on defoliation. Defoliation occurred in all treated plants after the second and third PBZ treatments were applied. By Jan. 2017, 18 plants had light defoliation $(<30 \%)$, six were in the medium category $(30 \%$ to $50 \%)$, and 24 suffered severe defoliation $(>50 \%)$. As shown in Table 2, plants treated with $50 \mathrm{ppm}$ PBZ had the lowest degree of defoliation, whereas plants treated with $750 \mathrm{ppm}$ suffered the most. In comparison, applying $8 \mathrm{~g}$ of urea worsened the defoliation effect of $50 \mathrm{ppm}$ PBZ but lessened the effect of $750 \mathrm{ppm}$ PBZ. Pearson correlation analysis found a weak relationship of defoliation severity with the flower bud number and abscission (absolute $R$ values were lower than $0.35, P$ value $<0.05$ ).

Effects of urea and $P B Z$ on growth. Treatments with combined urea and PBZ did not affect the growth of stem basal diameter because there was no significant difference between the treated plants and control $(P>0.05)$. In contrast, plants treated with $\mathrm{T} 4$, or $\mathrm{T} 11$ to $\mathrm{T} 16$ were significantly shorter than the control group, suggesting that these treatment types affect height growth. All these treatments include either high urea or PBZ (Fig. 4).

When the plants were grouped based on defoliation severity (light $<30 \%$, medium $30 \%$ to $50 \%$, and severe $>50 \%$ ), no statistical difference in stem basal diameter was detected among them. In terms of height, plants that suffered severe defoliation were significantly shorter than the ones having light defoliation (Fig. 5). There was also a weak positive relationship between plant the height and diameter $(R=0.40, P$ value $=0.0004)$.

Relative chlorophyll content and $C / N$ ratio. There was no significant difference in relative chlorophyll content among the treatments and control. A weak negative correlation was found between relative chlorophyll content and plant basal diameter $(R=-0.31$, $P$ value $=0.028)$. $\mathrm{C}$ and $\mathrm{N}$ contents were measured for three time periods: before treatments were applied (Apr. 2016), when flower buds developed rapidly (Sept. 2016), and when flower buds started to break in Jan. 2017. Because of budget constraints, leaf samples of three plants within the same treatment types were pooled for $\mathrm{C}$ and $\mathrm{N}$ analysis. As a result, there is no statistical power in this set of data. However, positive correlation was found between the plant height and $\mathrm{C} / \mathrm{N}$ ratio measured in September $(R=0.45, P$ value $=0.001)$ and January $(R=$ $0.35, P$ value $=0.02)$ and between plant basal diameter and $\mathrm{C} / \mathrm{N}$ ratio measured in April $(R=0.37, P$ value $=0.008)$ and September $(R=0.61, P$ value $<0.001)$. This indicates that plant growth is affected by $\mathrm{C} / \mathrm{N}$ balance.

\section{Discussion}

As a landscaping and a high-end indoor potted plant, golden camellia is highly prized for its flowers' large size and unique color. In addition to their aesthetic appeal, golden camellia flowers are valued for tea because they contain chemical compounds that may support good health (Lin et al., 2013; Wang et al., 2015). Compared with red, purple, pink, or white camellia flowers, golden camellia flowers are rare, despite their high market demand. Among the yellow-flowered camellia species, $C$. chrysantha is the first discovered and best known. In this study, we treated 4-year-old grafted $C$. chrysantha plants with urea and PBZ and successfully increased flowering intensity. This is the first report on flower induction in a golden species with PBZ. To our knowledge, the only previous report that used PBZ for Camellia growth and flowering was on cuttings of two hybrids of a crossing of Camellia saluenensis with Camellia japonica (Wilkinson and Richards, 1988). These two red-flowered species belong to sections different from the golden camellias. In addition, the effect of PBZ on flowering differed between the two cultivars included in the study, whereas the plant height was reduced by $\approx 30 \%$ (Wilkinson and Richards, 1988). In another study, Luo et al. (2013) successfully increased the flower number in mature $C$. chrysantha seedlings (15-20 years old, basal diameter $3.0-3.9 \mathrm{~cm}$ ) with ethephon. However, the optimal concentration for flower induction, 2.50 $\mathrm{mg} \cdot \mathrm{L}^{-1}$, caused smaller flowers and leaf area. Sprouting of new shoots was also severely affected with this concentration. According to a report on guava (Psidium guajava L.) plants, PBZ was found more effective in increasing the fruit number, fruit yield, yield efficiency, and fruiting density than ethephon (Brar and Bal,

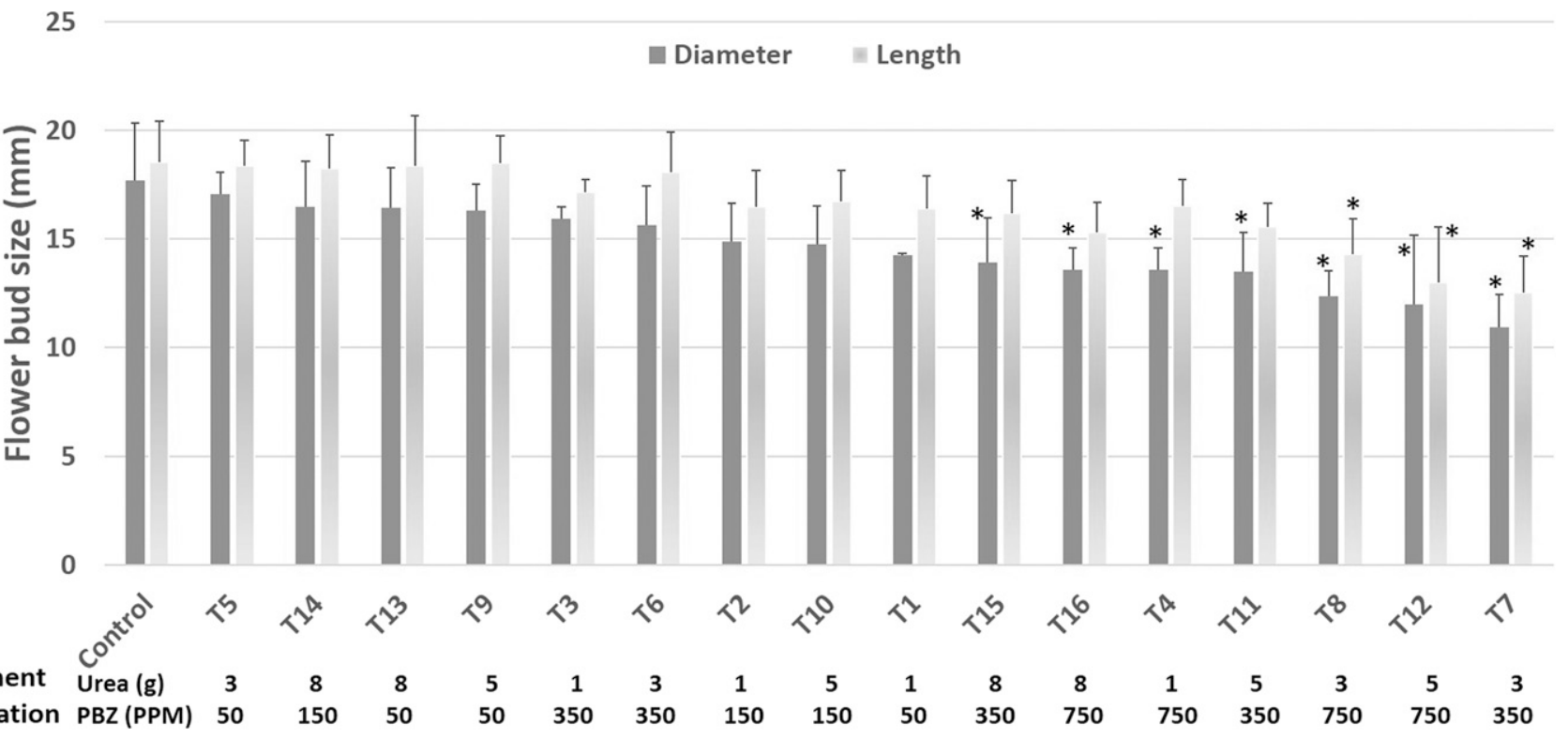

Fig. 3. Diameter and length of flower buds on Camellia chrysantha plants treated with paclobutrazol and urea (T1-T16). Measurements were taken in Jan. 2017. * indicates significant difference from control at $P<0.05$. 
2010). Therefore, we decided to include PBZ in our experiment.

The $C$. chrysantha plants used in our study were grafted on 1.5-year-old $C$. osmantha rootstocks in Aug. 2012 using 0.5- to 1-yearold shoots. By 2016 when our experiments started, none of these plants had flowered.

Table 2. Defoliation of Camellia chrysantha plants treated with paclobutrazol (PBZ) and urea, with dark green representing $<5 \%$ defoliation, dark red $>50 \%$, and yellow between $5 \%$ and $50 \%$.

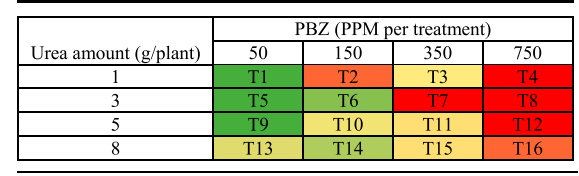

This was expected because it usually takes 5 or 6 years and a basal stem diameter of at least $2.5 \mathrm{~cm}$ for grafted plants to set flower buds (Chai et al., 2009; Jiang and Zhao, 1997). While all trees included in the study were close to 5 years old, their basal diameters were smaller than $2 \mathrm{~cm}$ by the Spring of 2017. The fact that the three control plants, which received a single foliar spray of 800 ppm in May 2016, all produced flower buds for the first time in 2016 reaffirms the efficacy of PBZ. Because the mode of action of PBZ is the inhibition of GA synthesis in plants, our results suggest that decreasing GA level benefits flower bud initiation in C. chrysantha.

There are reports showing effects of nitrogenous compounds, such as urea, in

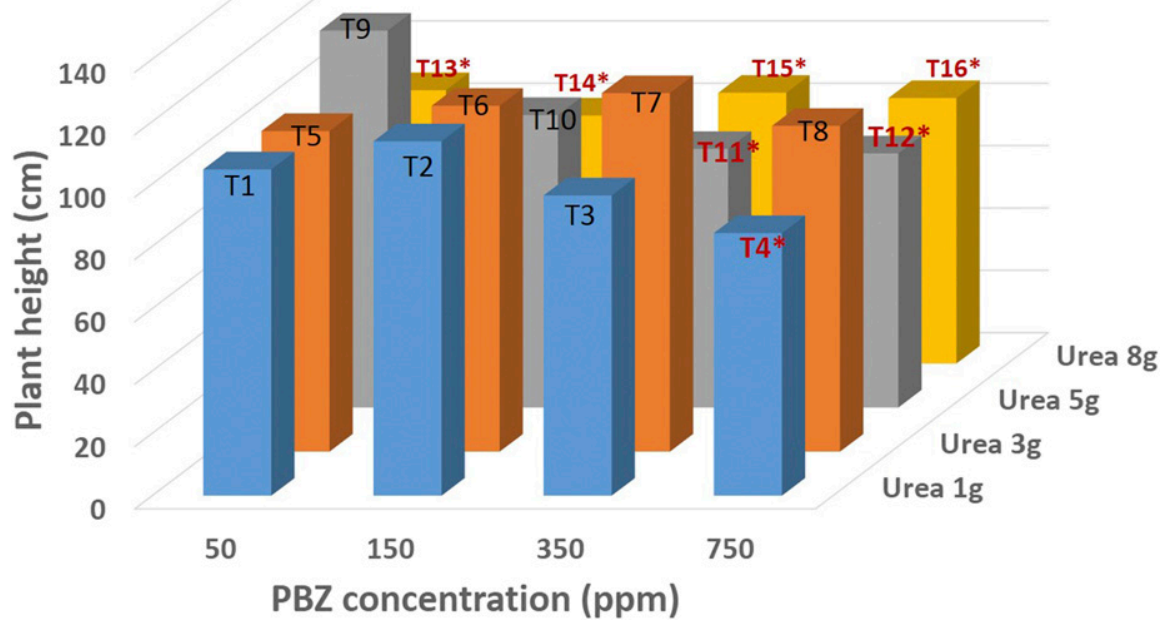

Fig. 4. Heights of Camellia chrysantha plants treated with paclobutrazol and urea (T1-T16). Measurements were taken in Jan. 2017. * indicates significant difference from control at $P<0.05$.

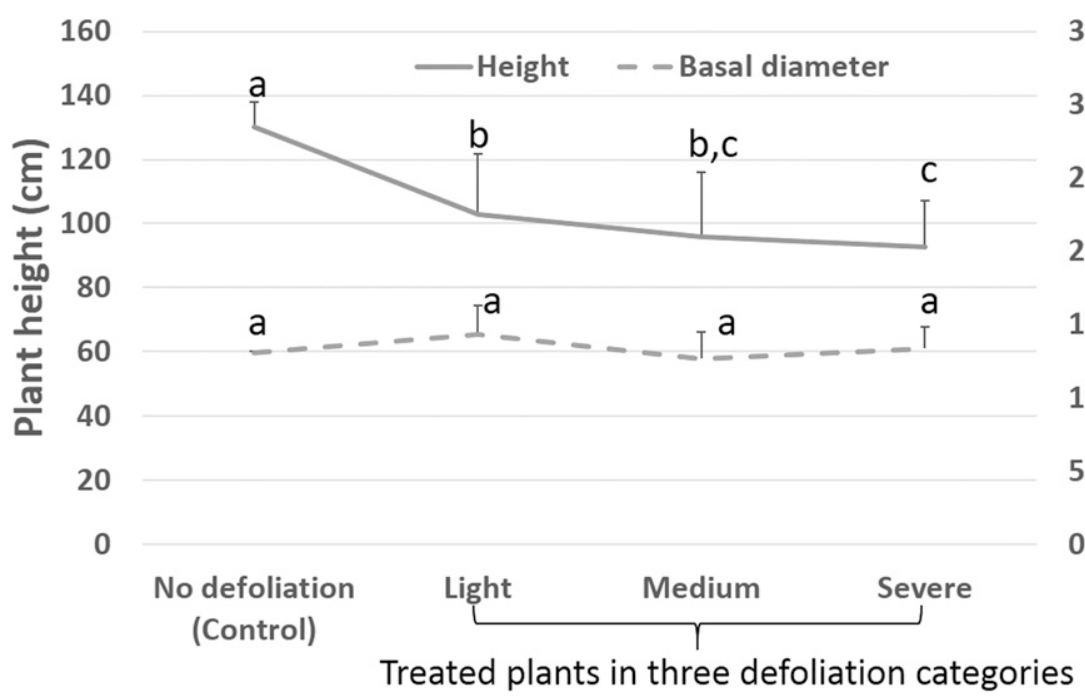

Fig. 5. Camellia chrysantha plant height and basal diameter grouped by defoliation severity. Measurements were taken in Jan. 2017. Defoliation was categorized into three groups: light $(<30 \%)$, medium (30\% to $50 \%)$, and severe ( $>50 \%)$. Within the same line, different letters indicate significant difference at $P<0.05$. increasing floral initiation and flowering intensity in both deciduous and evergreen species (Edwards, 1986; George and Nissen, 1993; Monselise, 1986; Nunez-Elisea, 1985). In particular, a study by Qi et al. (2012) compared nitrogen content in $C$. chrysantha shoots that had abundant, few, or zero flowers. It was found that shoots bearing abundant flowers contained more nitrogen, suggesting a role of nitrogen in flowering of C. chrysantha. In our study, urea, in combination with PBZ, effectively induced flowering in young $C$. chrysantha plants. Among the 16 urea and PBZ combinations, nine produced significantly more flower buds than the control (Fig. 2). A low PBZ concentration of $50 \mathrm{ppm}$ was effective only in combination with $5 \mathrm{~g}$ urea. When the PBZ concentration was increased to $150 \mathrm{ppm}$, combinations with 1 and $5 \mathrm{~g}$ urea was effective. At the concentration of $350 \mathrm{ppm}, \mathrm{PBZ}$ was effective with all four dosages of urea included in the study, i.e., 1, 3, 5, and $8 \mathrm{~g}$. At a higher concentration of $750 \mathrm{ppm}$, PBZ worked effectively with low dosages of urea ( 1 and $3 \mathrm{~g}$ ) in flower bud induction. These results indicate interactions of PBZ and urea: a low concentration of PBZ can be effective if it is in combination with a higher dosage of urea, whereas high concentrations of PBZ and lower dosages of urea are better combinations.

Flower bud abscission is normally high in camellias, with up to $50 \%$ in some cultivars (McElwee, 1952). This phenomenon was observed in all the flowered $C$. chrysantha plants in our study, with $22 \%$ of the plants dropping more than $50 \%$ of their flower buds. We suspect that the young age and the small size of our plants contributed to the high abscission rate considering that balancing vegetative and reproductive development is essential to survival and the fact that abscission rate was higher in plants producing more flower buds (Pearson $R$ value of 0.54 and a $P$ value of 0.03 ). After taking abscission into account, four treatments types, T2, T3, T7, and T11, produced an average of $11,11,16$, and 14 flowers per tree, respectively (Fig. 2). These numbers are significantly higher than the control, which only had two flowers per tree. Among these effective treatment combinations, $350 \mathrm{ppm}$ PBZ was included in T3, T7, and T11 and $150 \mathrm{ppm} \mathrm{PBZ} \mathrm{in} \mathrm{T2.} \mathrm{As} \mathrm{for}$ urea application, $\mathrm{T} 2$ and $\mathrm{T} 3$ contained $1 \mathrm{~g}$ of urea, whereas T7 contained $3 \mathrm{~g}$ and T11 $5 \mathrm{~g}$. Urea is a commonly used nitrogenous fertilizer because of its high nitrogen content and low cost. In our study, however, a high dosage of $8 \mathrm{~g}$ urea inhibited the flowering induction effect of $\mathrm{PBZ}$ at the concentrations of 50, 150, and $750 \mathrm{ppm}$. Whereas the combination of $8 \mathrm{~g}$ urea and $350 \mathrm{ppm}$ PBZ was initially effective in inducing more flower buds than the control, most of the induced flower buds dropped before they could open, leading to no significant difference between this treatment combination and the control. Therefore, combinations of lowdosage urea (1-3 g) with 150-350 ppm PBZ are most effective when taking flower bud abscission into account. 
Similar to experiments using ethephon (Luo et al., 2013), a high concentration of 750 ppm PBZ in our experiments significantly decreased either flower bud length, diameter, or both regardless of the dosage of urea (Fig. 3). Combinations including $350 \mathrm{ppm}$ also affected flower bud size except for T3 (350 ppm PBZ+1 g urea). The effect of PBZ on stem diameter depends on the concentration and species. For instance, Yelenosky et al. (1995) reported a reduction by $12 \%$ to $50 \%$ in citrus rootstock seedlings, whereas Berova and Zlatev (2000) and Tsegaw et al. (2005) observed an increase in tomato and potato. In contrast, PBZ consistently reduces the plant height in a range of species (Bañón et al., 2005; Mabvongwe et al., 2016; Pal et al., 2016; Terri and Millie, 2000). None of our treatment types had an influence on basal stem diameter. Neither did they change relative chlorophyll content, suggesting that photosynthesis is unaffected by the treatments. However, combinations that included either $750 \mathrm{ppm}$ PBZ or $8 \mathrm{~g}$ of urea significantly reduced the plant height, with the exception of T8, which was 750 PBZ+3 g urea. The concentration $750 \mathrm{ppm}$ PBZ also caused severe defoliation $(>50 \%)$, with the exception of T16 (750 ppm PBZ $+8 \mathrm{~g}$ urea) (Fig. 4). This may suggest that inclusion of an appropriate amount of urea can mitigate the effects of high concentrations of PBZ on the plant height and defoliation. When applied together, PBZ and urea may also have an additive effect on stem height reduction because it took a lower concentration of PBZ than $750 \mathrm{ppm}$ and a lower dosage of urea than $8 \mathrm{~g}$ to have a height reduction effect in T11 (350 ppm PBZ and $5 \mathrm{~g}$ urea). In addition, a lower concentration of $350 \mathrm{ppm}$ PBZ in combination with $3 \mathrm{~g}$ urea resulted in severe defoliation, indicating the existence of PBZ and urea interaction on defoliation. It is well known that environmental stresses, such as drought, poor nutrition, and defoliation, can stimulate flowering. For instance, 50\% and 75\% defoliation in kiwifruit vines could lead to about $25 \%$ and $53 \%$ increase of flower number, respectively (Cruz-Castillo et al., 2010). This stress-induced flowering may involve salicylic acid, the flowering gene FLOWERING LOCUS T, or both (Takeno, 2012). The fact that there exists positive correlation of defoliation severity with the flower bud number in our study (absolute $R$ values were lower than $0.35, P$ value $<0.05$ ) suggests the role of defoliation in precocious flowering of C. chrysantha.

To conclude, treatment types T2 (150 ppm PBZ +1 g urea) and T3 (350 ppm PBZ+3 g urea) can induce and sustain significant flowering in juvenile $C$. chrysantha grafted plants without negative effects on vegetative growth and flower bud size. Although defoliation was observed in the T2- and T3-treated plants, their severity was less than $50 \%$. This approach can be explored for both field and indoor golden camellia plants for flowering manipulation. Currently, we are in the process of observing the growth of the 2016-treated plants and examining if they will continue to flower in 2018 without further PBZ treatments in 2017. The carryover effect of PBZ seems to depend on multiple factors, such as species, tree age, method of application, and concentration, because so far, reports from various sources are not consistent. For instance, responses of two Eucalyptus species to high levels of trunk injection and collar drenching persisted for up to six growing seasons, yielding both increases in frequency of flowering and heaviness of bud crop (Griffin et al., 1993). In contrast, response to sprays and media drenches did not carry over into subsequent years in the two red camellia hybrids studied by Wilkinson and Richards (1988). In the future, it is important to study whether PBZ treatments change the chemical composition in flowers and leaves because they are popularly used as tea and to identify an optimized solution to minimize defoliation. It is also informative to investigate the potential flowering induction effect of PBZ on juvenile $C$. chrysantha seedlings.

\section{Literature Cited}

Bañón, S., J.A. Fernández, J. Ochoa, and M.J. Sánchez-Blanco. 2005. Paclobutrazol as an aid to reducing some effects of salt stress in oleander seedlings. Eur. J. Hort. Sci. 70:43-49.

Brar, J.S. and J.S. Bal. 2010. Role of paclobutrazol and ethephon in reproductive growth of 'Allahabad Safeda' guava (Psidium guajava L.) plants at different spacing. J. Hort. Sci. 5: $128-133$.

Berova, M. and Z. Zlatev. 2000. Physiological response and yield of paclobutrazol treated tomato plants (Lycopersicon esculentum Mill). Plant Growth Regulat. 30:117-123.

Blaikie, S.J., J. Kulkarni, and W.J. Muller. 2004 Effects of morphactin and paclobutrazol flowering treatments on shoot and root phenology in mango cv. Kensington Pride. Sci. Hort. 101: 51-68.

Chai, S.F., X. Wei, Y-S. Jiang, J.Q. Wei, S-Y. Jiang, and M-L. Wang. 2009. The flowering phenology and characteristics of reproductive modules of endangered plant Camellia nitidissina. J. Trop. Subtrop. Bot. 17:5-11.

Christov, C., I. Tsvetkov, and V. Kovachev. 1995. Use of paclobutrazol to control vegetative growth and improve fruiting efficiency of grapevines (Vitisvinifera L.). Bulg. J. Plant Physiol. 21:64-71.

Cruz-Castillo, J., D. Woolley, and F. Famiani. 2010. Effects of defoliation on fruit growth, carbohydrate reserves and subsequent flowering of 'Hayward' kiwifruit vines. Sci. Hort. 125:579-583.

Deng, G.Y., Z.D. Yang, and T.L. Lu. 2000. A brief review of research on yellow camellia in China (in Chinese with English abstract). J. Guangxi Agr. Biol. Sci. 19:126-130.

Edwards, G.R. 1986. Ammonia, arginine, polyamines and flower initiation in apple. Acta Hort. 179:363.

Fletcher, R.A. and G. Hofstra. 1988. Triazoles as potential plant protectants, p. 321-331. In: D. Berg and M. Plimpel (eds.). Sterol biosynthesis inhibitors: Pharmaceutical and agrochemical aspects. Ellis Harwood Ltd, Chichester, UK.

Gao, J. 2005. Collected species of the genus Camellia-An illustrated outline. Zhejiang Science and Technology Publishing House, Hangzhou, China.
George, A.P. and R.J. Nissen. 1992. Effects of water stress, nitrogen and paclobutrazol on flowering, yield and fruit quality of the lowchill peach cultivar, 'Flordaprince'. Sci. Hort. 49:197-209.

George, A.P. and R.J. Nissen. 1993. Effects of growth regulants on defoliation, flowering, and fruit maturity of the low chill peach cultivar Flordaprince in subtropical Australia. Austral. J. Expt. Agr. 33:787-795.

Griffin, A.R., P. Whiteman, T. Rudge, I.P. Burgess, and M. Moncur. 1993. Effect of paclobutrazol on flower-bud production and vegetative growth in two species of Eucalyptus. Can. J. For. Res. 23:640-647.

$\mathrm{Hu}, \mathrm{H} .1965$. New species and varieties of Camellia and Theopsis of China. Acta Phytotax. Sin. 10:131-142.

Jiang, S. and R. Zhao. 1997. Observation on biological characteristics of Camellia Parvipetala (in Chinese with English abstract). Guihaia 17:94-96.

Kulkarni, V.J. 1988. Chemical control of tree vigour and the promotion of flowering and fruiting in mango (Mangiferaindica L.) using paclobutrazol. J. Hort. Sci. 63:557-566.

Liang, S.Y. 1993. Golden Camellia. China Forest Press, Beijing, China.

Lin, J-N., H-Y. Lin, N-S. Yang, Y-H. Li, M-R. Lee, C-H. Chuang, C-T. Ho, S-C. Kuo, and T-D. Way. 2013. Chemical constituents and anticancer activity of yellow camellias against MDAMB-231 human breast cancer cells. J. Agr. Food Chem. 61:9638-9644.

Littell, R.C., G.A. Milliken, W.W. Stroup, R.D. Wolfinger, and O. Schabenberger. 2006. SAS for mixed models. 2nd ed. SAS Publishing, Cary, NC

Luo, C.X., H. Pan, and W.H. Liang. 2013. Effects of Ethephon on flowering of Camellia Sect. Chysantha Chang (in Chinese with English abstract). Guangxi For. Sci. 42:276-278.

Lurssen, K. 1988. Triazole plant growth regulators: Effects and mode of action, p. 305-320. In: D. Berg and M. Plimpel (eds.). Sterol biosynthesis inhibitors: Pharmaceutical and agrochemical aspects. Ellis Harwood Ltd, Chichester, UK.

Lü, J., R. Chen, M. Zhang, J.A.T. da Silva, and G. Ma. 2013. Plant regeneration via somatic embryogenesis and shoot organogenesis from immature cotyledons of Camellia nitidissima Chi. J. Plant Physiol. 170:1202-1211.

Ma, J-L., R-Q. Zhang, X-J. Wei, and Y. Hang. 2013. Preliminary study on grafting compatibility of Camellia osmantha and Camellia chrysantha (in Chinese with English abstract). Proceedings of the 3rd International Academic Forum on Yellow Camellia, Nanning, Guangxi, China, February, 21-23. p. 129133.

Mabvongwe, O., B.T. Manenji, M. Gwazane, and M. Chandiposha. 2016. The effect of paclobutrazol application time and variety on growth, yield, and quality of potato (Solanum tuberosum L.). Adv. Agr. Article ID 1585463, 5 pages, doi:10.1155/2016/1585463.

Mansuroglu, S., O. Karaguzel, V. Ortacesme, and M.S. Sayan. 2009. Effect of paclobutrazol on flowering, leaf and flower colour of Consolidao rientalis. Pak. J. Bot. 41:2323-2332.

McElwee, E.W. 1952. The influence of photoperiod on the vegetative and reproductive growth of the common Camellia. Proc. Amer. Soc. Hort. Sci. 60:473-478.

Ming, T.L. 2000. Monograph of the genus Camellia. Yunnan Science and Technology Press, Kunming, China (in Chinese). 
Monselise, S.P. 1986. Citrus, p. 87-108. In: S.P. Monselise (ed.). Handbook of fruit set and development. CRC Press, Boca Raton, FL.

Nunez-Elisea, R. 1985. Flowering and fruit set of a monoembryonic and a polyembryonic mango as influenced by potassium nitrate sprays and shoot decapitation. Proc. Florida State Hort. Soc. 98:179-183.

Nybom, H. and L.V. Bartish. 2000. Effects of life history traits and sampling strategies on genetic diversity estimates obtained with RAPD markers in plants. Perspect. Plant Ecol. Evol. Syst. 3:93-114.

Oliveira, C.M. and G. Browning. 1993. Studies on the induction of flowering in juvenile Prunusavium L. J. Hort. Sci. 68:731-739.

Pal, S., J. Zhao, A. Khan, N.S. Yadav, A. Batushansky, S. Barak, B. Rewald, A. Fait, N. Lazarovitch, and S. Rachmilevitch. 2016. Paclobutrazol induces tolerance in tomato to deficit irrigation through diversified effects on plant morphology, physiology and metabolism. Sci. Rpt. 6:39321.

Park, C.R. 2000. Breeding progress with yellow camellia (American Camellia Yearbook). American Camellia Society, Fort Valley, GA.

Qi, X.X., X. Wei, S.Y. Cai, W.X. Jun, and Y.S. Jiang. 2012. The relationship of blossom of Camellia nitidissima and SPAD value and nitrogen content. Lishizhen Med. Mater. Med. Res. 23:2963-2965. (in Chinese with English abstract).

Rademacher, W. 2000. Growth retardants: Effects on gibberellin biosynthesis and other metabolic pathways. Annu. Rev. Plant Physiol. Plant Mol. Biol. 51:501-531.

SAS Institute, Inc. 2009. SAS/STAT 9.2 user's guide. 2nd ed. SAS Institute Inc., Cary, NC.

Shinichi, N., H. Fumio, S. Keiichi, and S. Yusuke. 2004. Petal coloration of interspecific hybrids between Camellia chrysantha $\times C$. japonica. J. Jpn. Soc. Hort. 73:189-191.
Stinchcombe, G.R., E. Copas, R.R. Williams, and G. Arnold. 1984. The effects of paclobutrazol and daminozide on the growth and yield of cider apple trees. J. Hort. Sci. 59:323-327.

Song, L., X. Wang, X. Zheng, and D. Huang. 2011. Polyphenolic antioxidant profiles of yellow camellia. Food Chem. 129:351-357.

Stewart, W.M. 2002. Fertilizer contributions to crop yield. News and Views, Potash and Phosphate Institute, Norcross, GA.

$\mathrm{Su}$, K. 2010. Development of golden camellias in Guangxi (in Chinese). J. Guangxi Agr. 25:98100.

Takeno, K. 2012. Stress-induced flowering, p. 331345. In: P. Ahmad and M.N.V. Prasad (eds.) Abiotic stress responses in plants: Metabolism, productivity and sustainability. Springer, New York, NY.

Terri, W.S. and S.W. Millie. 2000. Growth retardants affect growth and flowering of Scaevola. HortScience 35:36-38.

Tsegaw, T., S. Hammes, and J. Robbertse. 2005. Paclobutrazol-induced leaf, stem, and root anatomical modifications in potato. HortScience 40:1343-1346.

Tuyama, T. 1975. On Theopsis chrysantha Hu. J. Jpn. Bot. 50:297-299.

Wang, D-X., H. Ye, J-L. Ma, and Z-D. Zhou. 2014. Evaluation and selection of Camellia osmantha germplasm resources (in Chinese with English abstract). Nonwood For. Res. 32:159162.

Wang, W., H. Liu, Z. Wang, J. Qi, S. Yuan, W. Zhang, H. Chen, J.W. Finley, L. Gu, and A-Q. Jia. 2015. Phytochemicals from Camellia nitidissima Chi inhibited the formation of advanced glycation end-products by scavenging methylglyoxal. Food Chem. 205:204-211.

Wilkinson, R.L. and D. Richards. 1988. Influence of paclobutrazol on the growth and flowering of
Camellia $\times$ Williamsii. HortScience 23:359360 .

Williams, M.W. 1984. Use of bioregulators to control vegetative growth of fruit trees and improve fruiting efficiency. Acta Hort. 146:97104.

Williams, D.R., B.M. Potts, and P.J. Smethurst. 2003. Promotion of flowering in Eucalyptus nitens by paclobutrazol was enhanced by nitrogen fertilizer. Can. J. For. Res. 33:74-81.

Xing, F.W. 2005. Rare plants of China. Hunan Education Publisher, Changsha, p. 112-113 (in Chinese).

Xu, Z.R. 1995. A study of the vegetation and floristic affinity of the limestone forests in southern and southwestern China. Ann. Missouri Bot. Gard. $82: 570-580$

Yadav, R.K., N. Rai, D.S. Yadav, and B.S. Asati. 2005. Use of paclobutrazol in horticultural crops-A review. Agr. Rev. 26:124-132.

Yelenosky, G., J.C.V. Vu, and H.K. Wutscher. 1995. Influence of paclobutrazol in the soil on growth, nutrient elements in the leaves, and flood/freeze tolerance of citrus rootstock seedlings. J. Plant Growth Regul. 14:129-134.

Zhang, H.D. and S.X. Ren. 1998. Flora of China. Science Publisher, Beijing, China. Vol. 49, p. 101-102.

Zheng, R.R., Y. Wu, and Y.P. Xia. 2012. Chlorocholine chloride and paclobutrazol treatments promote carbohydrate accumulation in bulbs of Lilium Oriental hybrids 'Sorbonne'. J. Zhejiang Univ. Sci. B 13:136-144.

Zhu, X.H., K.Y. Lu, and Y.H. He. 2007. Historical and future development of Camellia reticulate in Yunnan (in Chinese). (Proc. Chin. Soc. Sci. Annu. Symp.).

Zhuang, R.L. 2008. Chinese oil-tea Camellia. 2nd ed. Chinese Forestry Publishing House, Beijing, China. 